\title{
Investigation of Benzo-[a]-Pyrene Residue on Palestinian Olive Fruits and in Olive Oil
}

\author{
Orwa Jaber Houshia, ${ }^{1 *}$ Najat Al-daqqa, ${ }^{1}$ Tahani Alawneh, ${ }^{1}$ Ismail Elmasri ${ }^{2}$ \\ ${ }^{1}$ Department of Chemistry \\ ${ }^{2}$ College of Dental Surgery \\ The Arab American University, P.O.Box 240, Jenin, Palestine \\ orwa.housheya@aauj.edu
}

\begin{abstract}
Olive trees, fruits and oil play an essential part of the Mediterranean life, culture, economy and diet. Taking good care the trees, fruits and oil is one of the main concerns to the farmers in Palestine, because of the impact on the final quality of olives. Proximity of the olive tree to streets frequented by high traffic diesel trucks influences the overall health of the trees that affects quality of the product. Exhaust emission from diesel engines releases by product called Polycyclic Aromatic Hydrocarbons (PAH's), which are known to be carcinogenic agents. The purpose of the project is to analyze olive fruits and olive oil for the presence of such chemicals using Solid-Phase Extraction (SPE) followed by Thin Layer Chromatography (TLC) and U.V. Florescence for rapid Detection. Interesting results were obtained and showed that most olive oil samples tested negative, while the olive fruits tested positive for PAH's.
\end{abstract}

Keywords: Olive oil, Polycyclic aromatic hydrocarbon, SPE, TLC.

\section{Introduction}

Benzo-[a]-Pyrene or $(\mathrm{B}[\mathrm{a}] \mathrm{P})$ is a category of PAH that is toxic and carcinogenic to human. It also has some mutagenic properties as described by the World Health Organization [1,2]. Polycyclic Aromatic Hydrocarbons (PAH's) are a group of aromatic rings that do not contain any heteroatom [3,4]. Molecules composed of

$1 *$ AKA: Arwah Jaber Housheya 
two fused benzene rings are commonly known as naphthalene. Those with three fused benzene rings are called Anthracenes, and Phenanthrene, which is more stable than its linear isomer anthracene. The four fused benzene rings is called Pyrene and the five fused rings are known as Benzo-[a]-Pyrene, and the seven fused benzene rings is called Coronene, and so on as shown in Figure 1. Because PAH's differ in the number of benzene rings, their physical and chemical characteristics is also different. The aqueous solubility and vapor pressure for PAH's are low and decrease with rising molecular size. As a result, PAH's differ in their actions, allocation in the nature, and their impact on biological systems [3]. In general, PAH's are the byproduct of the incomplete combustion of coal, oil and gas, garbage, tobacco and exhausts of diesel engines. They can be found in dirt, air, food crops and groundwater [5,6]. PAH's exhibit some lipophilic properties and thus are more soluble in oil than aqueous solution as a function of increasing molecular size [7]. Consequently, these PAH's pose a threat during olive harvesting season, especially olive groves located near polluted-high traffic streets.

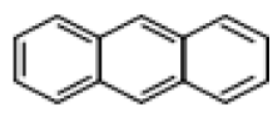

Anthracene

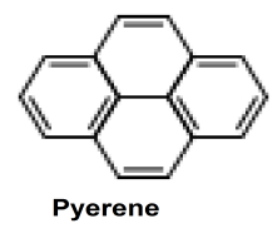

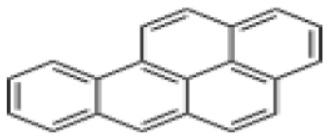

benzo-a-pyrine<smiles>c1cc2ccc3ccc4ccc5ccc6ccc1c1c2c3c4c5c61</smiles>

Coronene

Figure 1: An example of the PAHs

Analysis or detection of PAH's is frequently made by employing Gas Chromatography Mass Spectrometry (GC-MS). Alternatively, High Pressure Liquid Chromatography (HPLC) may be used alongside ultraviolet-visible or fluorescence spectroscopic methods or indicator strips [8-10]. The purpose of this research is to analyze olive fruits and olive oil for $\mathrm{B}[\mathrm{a}] \mathrm{P}$ only, since it is relatively the most dangerous and may have high level of toxicity resulting in larger health impact than any other PAH identified in the environment [11-13]. The maximum Contamination Level (MCL) for B[a]P has been set at $0.0002 \mathrm{ppm}$. Here, we employed Solid-Phase Extraction (SPE) followed by Thin Layer Chromatography (TLC) and U.V. Florescence for rapid detection. 


\section{Methodology}

\subsection{Solid-phase extraction setup}

Solid-phase extraction (SPE) is a separation method by which compounds that are dissolved in a liquid mixture (mobile phase) are separated from other compounds in the mixture according to their physical and chemical properties. SPE has four different phases that is Reversed phase, Normal phase, Ion exchange phase and Adsorption phase. When components of interest are present at low levels, the normal phase is usually employed. A typical normal solid phase extraction involves four basic steps. First, the cartridge is equilibrated with a non-polar solvent or slightly polar, that wets the external and penetrates the bonded phase. Next water, or buffer of a like constitution as the sample, is normally cleaned across the column to soak the silica surface. The sample is next added to the cartridge. As the sample passes across the stationary phase, the analytes in the sample will interact and retain on the sorbate, while the solvent, salts, and supplementary impurities bypass across the cartridge. Afterward the sample is loaded; the cartridge is cleaned with buffer or solvent to remove more impurities. Then, the analyte is eluted with a non-polar solvent or a buffer of the appropriate $\mathrm{pH}$. A stationary phase of polar functionality bonded silicas makes up the solid phase. This stationary phase will adsorb polar molecules that can be combined along with the polar solvent. The cartridge has matrix of magnesium silicate $(\mathrm{MgO}-\mathrm{SiOH} 15: 85)$ of high purity and a particle size 150-250 $\mu \mathrm{m}$.

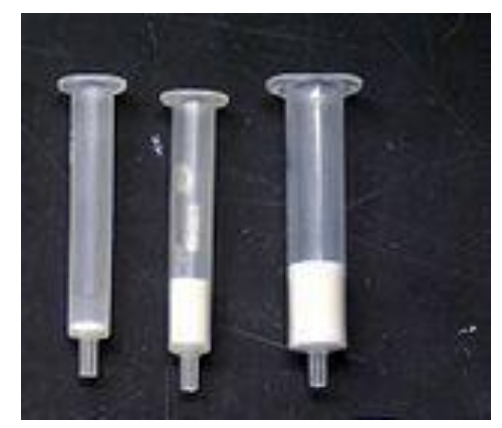

Figure 2: A special SPE cartridge for B[a]P extraction

\subsection{Thin layer chromatography plates}

Thin layer chromatography (TLC) is a liquid-solid adsorption method whereas by capillary action, the mobile phase climb the stationary phase of Nano silica that coated with specific external (BET) $\sim 500 \mathrm{~m}^{2} / \mathrm{g}$, mean pore size $60 \AA$, specific pore volume $0.75 \mathrm{~mL} / \mathrm{g}$, particle size $2-10 \mu \mathrm{m}$; impregnated alongside caffeine, an electron acceptor for PAH scrutiny established on charge-transfer [15].

\subsection{UV- Florescence Detection}


After the plates are totally dried, a UV-fluorescence is utilized to visualize and detect the spots that gives purple-blue color below UV-light (near to $366 \mathrm{~nm}$ ). This aids in computing the intensity and area of each spot traveling a distance on TLC plat. Measured intensity of $\mathrm{B}[\mathrm{a}] \mathrm{P}$ standard was compared with those obtained from the olive oil sample to determine the match between the standard and the sample.

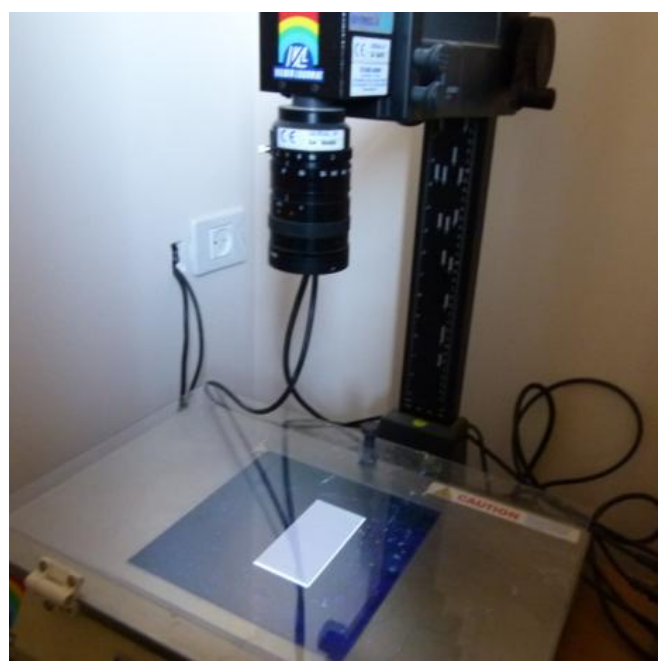

Figure 3: U.V. Lamp Instrument setup

\subsection{Chemicals and materials}

Methanol and n-Hexane were used for washing and conditioning of the SPE cartridges. n-Hexane also used for elute the PAH's from SPE cartridges, Dichloromethane (DCM) was used as mobile phase in TLC, SPE column (CHROMABOND®FLORISIL®/6ml/1000mg) by Macherey-Nagel (MN) for PAH application (MN appl.No. 301290). TLC plates (Glass plates Nano-SILPAH,10x10 cm). The UV- fluorescence instrument. Standard stock solution of $\mathrm{B}$ [a]P was analytically prepared in $\mathrm{n}$-hexane solvent to a final concentration of 10ng mL-1 and were retained free from light. The standard were made at 1, 2, 5, and $10 \mathrm{ng} / \mathrm{ml}$ concentrations before spotting on the TLC plates.

\subsection{Sample Preparation}

The olive fruits were crushed using a mortar and a pestle to extract the crude oil. About $1 \mathrm{~g}$ of the crude oil sample was used for the SPE column. Then $10 \mathrm{ml}$ of $\mathrm{n}$ hexane was added to each sample to dissolve the oil and lower the viscosity and to enhance the extracted product and minimize cross contaminations. 


\section{Results and Discussion}

Some olive fruits samples were collected directly from olive groves that are adjacent to main road and highways within Jenin Governorate, WestBank Palestine. Other olive oil samples were collected from the olive oil press as shown in Table-I. Each olive oil sample was about $50 \mathrm{~mL}$ collected in conical plastic tube, and olive fruits amount ranged from 70 grams to 250 grams. All samples were kept in refrigerator until needed. For the SPE cartridges $(1000 \mathrm{mg} / 6 \mathrm{ml})$ were conditioned with $20 \mathrm{ml}$ methanol and $20 \mathrm{~mL}$-hexane as shown schematically in the following sketch:

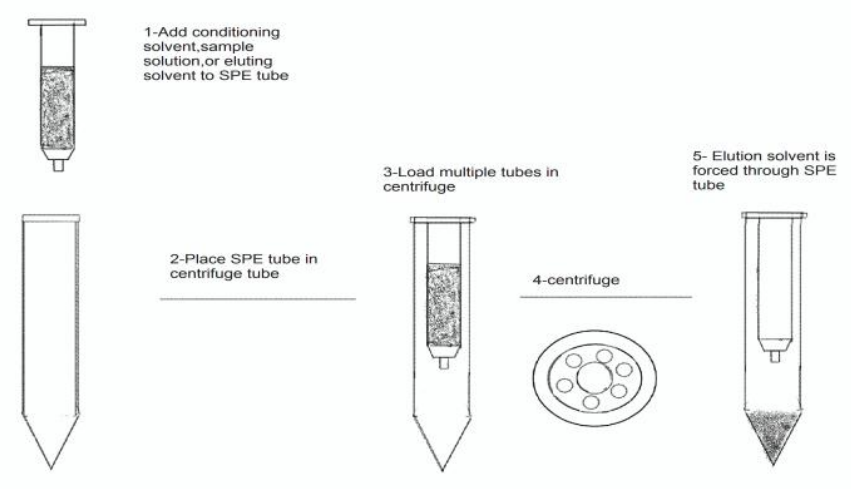

Figure 4: a sketch of the SPE setup

Table I: Description of target sites and samples collected

\begin{tabular}{lllll}
\hline No. & Sample name & Description & Amount & Origin \\
\hline 1 & Jabriat street & Oil & $50 \mathrm{ml}$ & Jabriat town \\
2 & Al-hadaf & Oil & $50 \mathrm{ml}$ & Jenin \\
3 & Ajja street & Oil & $50 \mathrm{ml}$ & Groves behind the dump \\
4 & AAUJ street, East & Olive-fruit & $100 \mathrm{~g}$ & Trees off street by 1/2meter \\
5 & AAUJ street, South & Olive-fruit & $100 \mathrm{~g}$ & South side of the University \\
6 & Arraba-koferai & Olive-fruit & $100 \mathrm{~g}$ & Arraba-koferai street \\
7 & Arraba street & Olive-fruit & $100 \mathrm{~g}$ & Arraba town \\
8 & Al-hadaf & Olive-fruit & $150 \mathrm{~g}$ & Jenin \\
9 & Koferai & Olive-fruit & $250 \mathrm{~g}$ & Koferai town \\
10 & Raba & Olive-fruit & $100 \mathrm{~g}$ & Raba town \\
11 & Yabad & Olive-fruit & $250 \mathrm{~g}$ & Yabad town \\
12 & Beer-Albasha & Olive-fruit & $70 \mathrm{~g}$ & Beer-Albasha Nablus street \\
\hline
\end{tabular}

Oil samples were eluted through the preconditioned extraction cartridge (SPE cartridge) using centrifuge. The elution of the PAH's was made with n-hexane (25 $\mathrm{mL})$. The eluate was evaporated to dryness in water path overnight. After PAH 
was extracted from oil, the residual from elution was around to $1 \mathrm{ml}$. Using $10 \mathrm{Ml}$ micropipette syringe one spot from each sample was made onto the TLC plate and compared with standard references solution for quantitative analysis. Prior to use, TLC plates were heated on hot plat to dryness (to activate the plate and remove humidity). Because Dichloro-Methane (DCM) solvent was used as a mobile phase, the TLC apparatus was placed in refrigerator at low temperature.

The UV lamp was held over the plate, facing down, and mark with a pencil any spots which gave blue color, tracing around their outline. The purpose of TLC plate was to compare the fluoresce intensity of the $\mathrm{B}[\mathrm{a}] \mathrm{P}$ from the extracted samples with those from the B[a]P reference (known) standard. This can be seen in this Figure 5

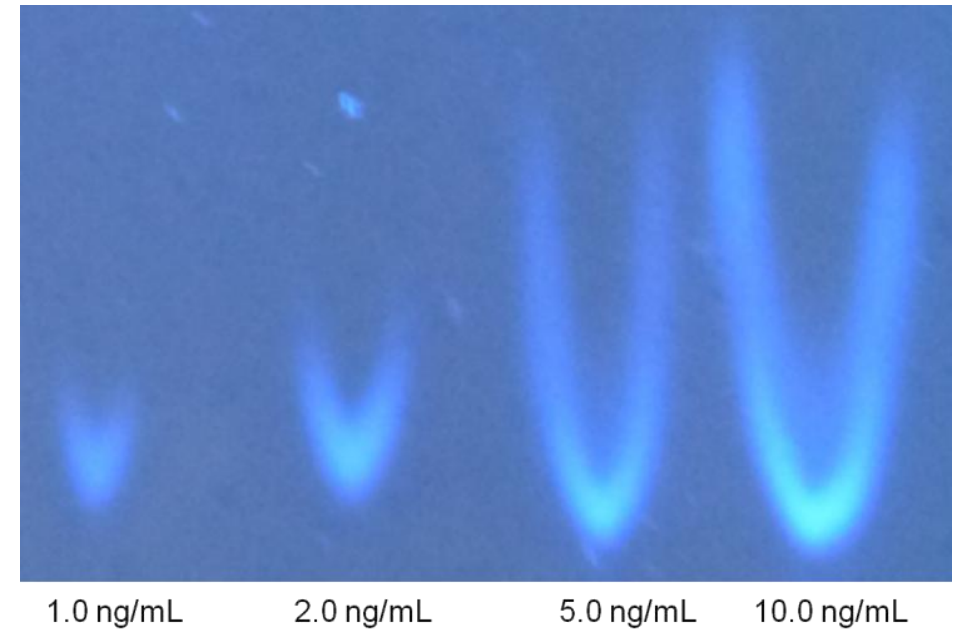

Figure 5: B[a]P standard solutions on TLC plates

The concentration of standards were $1,2,5$, and $10 \mathrm{ng} / \mathrm{ml}$ and its corresponding spot intense areas were calculated from the TLC plate. A calibration curve was plotted of intensity versus concentration and a linear equation was obtained as shown in Figure 6. Then the intensity for the run samples was fit using the linear equation from which the concentration of the samples was calculated. 


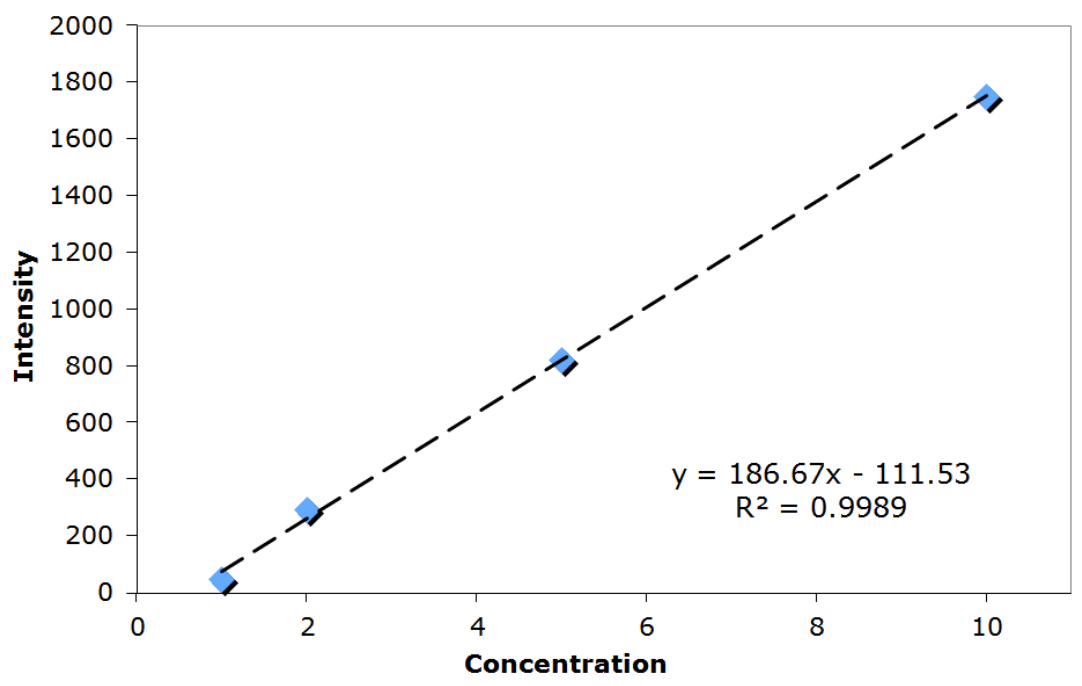

Figure 6: Calibration curve of standard $\mathrm{B}[\mathrm{a}] \mathrm{P}$ solutions

Results of the calculations for all samples collected are shown in Table-II.

Table II: Summary of results

\begin{tabular}{llll}
\hline No. & Sample name & B[a]P & $\begin{array}{l}\text { Conc. of B[a]P } \\
(\mathrm{ppm})\end{array}$ \\
\hline 1 & Jabriat street & Negative & -- \\
2 & Al-hadaf & Negative & -- \\
3 & Ajja street & Positive & 0.0063 \\
4 & AAUJ street-South & Negative & -- \\
5 & AAUJ street-East & Positive & 0.006 \\
6 & Arraba - koferaai street & Positive & 0.011 \\
7 & Arraba - street & Negative & -- \\
8 & Al-hadaf & Positive & 0.00733 \\
9 & Koferai & Positive & 0.006833 \\
10 & Raba & Positive & 0.00666 \\
11 & Yabad & Positive & 0.01333 \\
12 & Beer-Albasha & Negative & -- \\
\hline
\end{tabular}

Here, seven samples showed positive B[a]P test with respect to location. Samples adjacent to heavy traffic roads frequented by diesel trucks showed higer concentration. Because of their low solubility in water and high affinity for organic carbon, PAHs are founded in oil. Sample no.5 ( Aauj-street) contains $0.006 \mathrm{ppm}$ of B[a]P, otherwise sample no.11 (Yaabad) contains $0.01333 \mathrm{ppm}$ of $\mathrm{B}[\mathrm{a}] \mathrm{P}$. These numbers are indicators that as the olive tree closest from street as the concentration of $\mathrm{B}[\mathrm{a}] \mathrm{P}$ increasing. Sample no. 8 gave positive $\mathrm{B}[\mathrm{a}] \mathrm{P}$ test from 
Alhadaf location with $0.00733 \mathrm{ppm}$. By contrast, sample no. 2 from same area gave negative test. This result was surprising but not inconsistent with literature. Upon closer inspection, notice that the nature of the two samples are different. Sample no. 2 was obtained from already processed oil at olive mill. While sample no. 8 was obtained from fruits in the area and processed in the laboratory. Because olive oil mill have washing procedure which remove any residue on fruits, the $\mathrm{B}[\mathrm{a}] \mathrm{P}$ and other contaminants are removed during this cleansing step, and thus the oil would have no $\mathrm{B}[\mathrm{a}] \mathrm{P}$ residues.

Sample no.11 had the greatest amount of B[a]P. This is because the sample was collected from olive trees that are close to the charcoal factories in Yabad. Also sample no.6 (Arraba - koferai street), possess a high concentration of $\mathrm{B}[\mathrm{a}] \mathrm{P}(0.011$ $\mathrm{ppm}$ ) because of the proximity of the olive tree to the main street between Arraba and Koferai, that is frequented by high traffic volume.

It is noteworthy to mention that the Maximum Contamination Level (MCL) of $\mathrm{B}$ [a]P is $0.0002 \mathrm{ng} / \mathrm{L}$. Thus positive samples that are above the MCL are more likely to be carcinogenic and mutagenic for humans. This depend on many factors include the dose (how much), and your individual characteristics such as age, sex, nutritional status, family traits, lifestyle, and state of health.

\section{Conclusions}

Polycyclic Aromatic Hydrocarbons will continue to be present in the environment due to combustion of fossil fuel in diesel engines. The simple test we used indicated that olive tree closer to roads with high traffic volume may contain varying concentration of $\mathrm{B}[\mathrm{a}] \mathrm{P}$. This can be overcome by washing olive fruits meticulously before processing them in the olive oil mills, and new olive trees be planted farther away from main roads. It is recommended that olive fruits also be washed well with water before pickling it. Overall, we believe that Palestinian olive oil would possess zero to a negligible amount of $\mathrm{B}[\mathrm{a}] \mathrm{P}$ considering that most trees lie farther away from streets.

\section{ACKNOWLEDGEMENTS}

Great appreciation is expressed to all farmers in the towns mentioned in the research who donated samples generously.

\section{References}

[1] ATSDR. 1996." Toxicological profile for Polycyclic Aromatic Hydrocarbons." Agency for Toxic Substances and Disease Registry, Atlanta, GA:U.S. department of Health and Human Services, Public Health Service. 
[2] Luch, A. (2005). The Carcinogenic Effects of Polycyclic Aromatic Hydrocarbons. London: Imperial College Press. ISBN 1-86094-417-5.

[3] Fetzer, J. C. (2000). "The Chemistry and Analysis of the Large Polycyclic Aromatic Hydrocarbons". Polycyclic Aromatic Compounds (New York: Wiley) 27 (2): 143.

[4] Xiaohong ,L. Xinhui , B. Bixian , M. Guoying , S. Jiamo ,F.(2004)." Separation of PAHs in aerosol by thin layer chromatography for compoundspecific stable carbon isotope analysis" (Talanta 66 (2005) 487-494)

[5] Neff (1979) and Handbook of Chemistry and Physics (Weast, 1968).

[6] Ramdahl, T, and Moller, M., 1983. Chemical and Biological Characterization of Emissions from a Cereal Straw Burning Furnace. Chemosphere, Vol. 12, 23-34.

[7] IPCS, 1998. Selected Non-heterocyclic Polycyclic Aromatic Hydrocarbons. Environmental Health Criteria 202. International Programme on Chemical Safety, World Health Organization, Geneva.

[8] Simon N. Platts ; Geophysical Laboratory: 5251 Broad Branch Road NW, Washington, DC 20015-1305: United States of America; the 'PAH World': Discotic polynuclear aromatic compounds as mesophase scaffolding at the origin of life; $p(1-2)$.

[9] Foth H, Kahl R, Kahl GF (1988) Pharmacokinetics of low doses of benzo(a)pyrene in the rat. Food and chemical toxicology, 26:45-51.

[10] IARC (1983) Polynuclear aromatic compounds, part 1: Chemical, environmental and experimental data. Lyon, International Agency for Research on Cancer, 477 pp. (IARC Monographs on the Evaluation of the Carcinogenic Risk of Chemicals to Humans, Vol. 32).

[11] IARC (1984) Polynuclear aromatic hydrocarbons, part 2: Carbon blacks, mineral oils and some nitroarenes. Lyon, International Agency for Research on Cancer, 365 pp. (IARC Monographs on the Evaluation of the Carcinogenic Risk of Chemicals to Humans, Vol. 33).

[12] Bjørseth A, Sortland O (1983) Long-range transport of polycyclic aromatic hydrocarbons. In: Bjørseth A, ed. polycyclic aromatic hydrocarbons. New York, NY, Marcel Dekker, pp. 507-524.

[13] Clar, E. Polycyclic Hydrocarbons, Academic Press (1964). 